Original Article

\title{
Clinical and Radiological Findings of Mandibular Cystic Lesions
}

Lovekesh Kumar, Suneel Kumar Punjabi, Sikander Munir Memon, Hira Yousuf, Shuja Aslam

ABSTRACT

OBJECTIVE: To determine the clinical and radiological findings of mandibular cystic lesions.

METHODOLOGY: This study was descriptive case series, conducted on $\mathbf{4 0}$ cases of mandibular cystic lesions at Oral \& Maxillofacial Surgery Department, Liaquat University of Medical \& Health Sciences, Jamshoro / Hyderabad from December 2015 to November 2016. Usually intraoral radiographs were done for radiological finding and CT scans where required for examining the extension of mandibular cyst. Among the features recorded on radiographs were involvement of the local anatomical structures, appearance of the cyst as multilocular or unilocular, root resorption of adjacent teeth and size. Data was analyzed by statistical software package SPSS version 20.0 .

RESULTS: During the study period, a total of $\mathbf{4 0}$ patients with clinico-radiographic and histopathological finding of mandibular cystic were included. Radiographically most radicular cysts $34(85.0 \%)$ appear as round unilocular radiolucent lesions in the periapical region. The most common type of cysts observed in the study were radicular cyst in 21 cases (14 males and 07 females) followed by dentigerous cyst in 11 $(27.5 \%)$ cases, odontogenic keratocyst in $5(12.5 \%)$ cases. Median mandibular cyst and others respectively. The main finding in this study was that there was no association or insignificant difference of types of cysts with age and gender. These types of cysts may occur equally in bother male and female ( $p$ value $>0.05$ ).

CONCLUSION: Evaluation of the results of this study shows that radicular cyst is the most common odontogenic cyst, coincident with the prevalence of dental caries.

KEYWORDS: Mandibular cystic lesion, Findings, Clinical, Radiological.

This article may be cited as: Kumar L, Punjabi SK, Memon SM, Yousuf H, Aslam S. Clinical and Radiological Findings of Mandibular Cystic Lesions. J Liaquat Uni Med Health Sci. 2018;17 (03):174-9. doi: 10.22442/jlumhs. 181730573

\section{INTRODUCTION}

Cyst is a pathological epithelial lined cavity containing fluid or semi fluid that can be either unilocular or multilocular ${ }^{1}$. Mandibular cyst clinically represents functional impairment due to bone remodeling and weakening or area result of secondary infection ${ }^{2}$. Mostly mandibular cyst can easily appreciated on conventional radiographs as radiolucent lesions ${ }^{2}$. Differentiation alone on radiographs is not sufficient for diagnosis and management ${ }^{1}$.

The etiology of the odontogenic cysts can be revealed by the presence of odontogenic cells that have remained entrapped within the bone or the gingiva that covers the mandible that is the epithelial cell rests of Malasezz, or the enamel organ or the dental lamina, hence giving rise to developmental cysts. However in certain cases the cysts may form due to an inflammatory process ${ }^{3}$. Developmental as well as inflammatory cysts are lesions that have an epithelial origin that are characterized by slow growth and have a tendency to expand and in spite of their benign biological course, they can grow up to considerable sizes if they are not diagnosed in time and treated suitably. Although the diagnosis of odontogenic cysts is based on various radiological and clinical features, however the final diagnosis is ascertained on the lesion's histopathology ${ }^{3}$.

These lesions present clinically with almost identical, limited sign and symptom of painless or painful swelling, loosening of tooth, facial deformity and sometimes sinus malformation. On radiology most of the lesions are unilocular or multilocular radiolucency. Hence, it is helpful in giving differential diagnosis only. Though, microscopic features are classical in most of the cases, it is difficult to differentiate lesions like, giant cell granuloma and cherubism, infected dentigerous cyst and infected radicular cyst, fibrous dysplasia and ossifying fibroma just on radiograph alone. Very few studies have been reported from Asia $^{4}$. Mandibular cyst can be classified on the basis of cell origin as odontogenic cyst or non-odontogenic cyst. Odontogenic cyst is the most common and 
frequently occurring cysts with ratio i.e. 2.25 times than non-odontogenic cyst ${ }^{1}$. Naz et al has found $98.9 \%$ odontogenic cysts with radicular cysts $(54.6 \%)$, dentigerous $(28.7 \%)$ and odontogenic keratocyst $(18.7 \%)^{5}$. Radicular cysts are the most prevalent odontogenic cysts comprising nearly two thirds cysts of mandible ${ }^{1}$. These Radicular cysts $(54.6 \%)$ are usually found in periapical region as round to pear shaped, radiolucent unilocular lesions which are mostly asymptomatic ${ }^{1}$. Dentigerous cysts radiographically shows a unilocular, radiolucent lesion characterized by well-defined sclerotic margins and associated with the crown of an unerupted tooth ${ }^{5,6}$. Odontogenic keratocysts are believed to arise from the dental lamina usually appears as a unilocular, radiolucent lesion with smooth, corticated borders that is often associated with an impacted tooth ${ }^{7}$.

Non odontogenic cystic lesions develop from osseous origin and are not tooth related however, when they are large enough it may be difficult to determine the relationship of the lesion to the adjacent teeth ${ }^{7}$. The non odontogenic cysts includes developmental cysts of the jaw like median mandibular cyst, nasopalatine duct cyst, nasolabial cyst ${ }^{1,8}$.

The diagnosis of mandibular cyst is complicated as most of the cyst are asymptomatic or present with non -specific symptoms. Conventional radiograph is therefore an essential diagnostic imaging for diagnosis as well as treatment and for monitoring response to treatment ${ }^{3,6}$ Mostly cases of extension of mandibular cysts can accurately be seen on computed tomography. Mostly mandibular cysts can be surgically removed by enucleation or marsupialization and examined microscopically to accurately establish the diagnosis ${ }^{3,6}$.

Among the developmental odontogenic cysts dentigerous cysts account for $24 \%$ of the cysts occur on jaw ${ }^{9}$. These cysts are well-defined true developmental pathologies found on jaws mostly related to impacted teeth commonly on permanent maxillary canines, mandibular $3^{\text {rd }}$ molar, and up to some extent the upper $3^{\text {rd }}$ molars and lower premolars ${ }^{10}$. They are commonly diagnosed on radiographic examination taken routinely or sometimes in later stages when the size of cyst significantly increases and are usually asymptomatic. However, the significance of the diagnosing dentigerous cysts on radiographs, there can be other reasons for the pericoronal space enlargement but no pathology revealed on histological examination.

Majority of the odontogenic cystic lesion were first miss diagnosed and treated by general dentist and majority were presented as late complication at tertiary care hospital of the city so it's frequency and best option for their management till not present; the rational of this study was to evaluate the presentation of different mandibular cysts and their management in patients visiting to our setup in order to reduce the morbidity and to increase its awareness in public.

\section{METHODOLOGY}

It was a descriptive case series study, sampling technique was non probability convenient, conducted on 40 cases for the period of one year at Oral \& Maxillofacial Surgery Department Liaquat University of Medical \& Health Sciences, Jamshoro/Hyderabad. Those patients whose age range was between 18 to 60 years either gender with clinico-radiographic finding of mandibular cystic lesion were included. While those patients who were not willing to participate in this study, medically compromised patient or patient with any contraindication to surgery were excluded from this study.

Informed consent was taken from the patient by researcher and the acceptance of this study was obtained from Ethical Committee Review Board of Liaquat University of Medical \& Health Sciences Jamshoro. A complete history of the patient with name, age, gender, presence or absence of swelling, tooth vitality/mobility, clinical findings like site of occurrence, presenting complaint and fluctuance, discharge, the aspiration of fluid, and nerve involvement in the lesion of the cystic were included. Radiological features of the cysts were recorded as seen on intraoral radiographs, OPG and periapical view. CT scans was required for examining the extension of mandibular cyst. Among the recorded radiographic features were mutilocular or unilocular appearance, involvement of the local anatomical structures, root resorption of the adjacent teeth and the size

After fulfilling the inclusion and exclusion criteria the purpose of this study was explained to all participants detail and written informed consent was taken from every participant. All patients with history, clinical examination, radiographic findings, (extra oral OPG and intra oral periapical as per need) and histopathological findings were performed. All patients' data was noted in the prescribed Proforma and all cases were done by consultant of department who has the experience of more than five years.

Surgical procedure: In the following procedure, local anesthesia was given with one cartridge of $1.8 \mathrm{ml}$ of Xyolcaine $2 \%$ with adrenaline 1:100000 (Medicaine). Later on the $10 \mathrm{cc}$ disposable syringe was used to aspirate the cystic lesions of mandible to see what type of fluid is driven blood, pus or watery fluid or air. After that incisional biopsy was done, incision was given with sterile surgical blade no 15 (company name: feather safety razor co. Ltd made in Japan). 
After incision soft tissue flap was reflected with the help of the periosteal elevator to expose the lesion, from this whole lesion, the small piece of the lesion was incised and put in the $10 \%$ formalin bottle. The flap was primary closed with sterile surgical suture of vicryl 3/0 (Johnson \& Johnson; made in USA) then the specimen and the fluid driven both were sent to the histopathological laboratory for the examination of definitive diagnosis. After the conformational of diagnosis by laboratory report all cystic lesions were treated accordingly.

Data Analysis: Data was analyzed by statistical software package SPSS version 20.0. Statistical analysis was expressed as frequencies and percentages. Descriptive statistics including patient's age, gender, age group, symptoms and signs of mandibular cysts, radiographic findings and management were entered and frequency and percentages were calculated. Mean+SD was calculated for quantitative variables like age of patient. Differences noted between the associations of age, gender and location of mandibular cysts were noted and tested via chi square and $p$ value $<0.05$ was considered as significant.

\section{RESULTS}

During the study period, a total of 40 patients with clinico-radiographic and histopathological finding of mandibular cystic were included based on inclusion and exclusion criteria. In the present study, the mean age \pm standard deviation (range) of the patients was $29.41 \pm 7.62$ (18 to 60 years). Minimum age was 18 years and maximum age range was 60 years. Most of the cases were observed in the age group 20 to 30 years in this study. Table No. I

Most of the patients $17(42.5 \%)$ were seen in the age group 18 to 30 years while second most common 13 $(32.5 \%)$ age group was 31 to 40 years. Periapical or radicular cyst $10(47.6 \%)$ and dentigerous cyst 5 $(45.4 \%)$ cases were observed in age group 18 to 30 years. Table No. I \& III

Out of 40 patients, $27(67.5 \%)$ were males and 13 $(32.5 \%)$ patients were females with male to female ratio of almost 2:1. Table No. I

In the present study, clinical findings were observed in all the patients. Swelling was found to be the most common finding presented in $33(82.5 \%)$ patients, aspiration of fluids was seen in $31(77.5 \%)$, discharge in $25(62.5 \%)$, pain was observed in $22(55.0 \%)$ patients and numbness was present only in $1(2.5 \%)$ patient. Table No. I In this study, radiographically most radicular cysts $34(85.0 \%)$ appear as round or pear-shaped unilocular radiolucent lesions in the periapical region. Four $(10.0 \%)$ patients were presented as multilocular while $35(87.8 \%)$ were presented as well defined only $5(12.5 \%)$ patients were ill defined and only $2(5.0 \%)$ were mixed. Table No. I. Out of 40 patients, $12(30.0 \%)$ cases were left sided and $28(70.0 \%)$ cases were right sided. Table No. I. In this study, microscopic re-examination of all available incisional/ excisional biopsy samples was taken. Incisional biopsy was performed in 33(82.5\%) patients while excisional biopsy was done in $7(17.5 \%)$ patients. In the present study, out of 40 patients, the type of cysts observed in the study were radicular cyst found in 21 cases (14 males and 07 females) followed by dentigerous cyst in 11 cases ( 7 males and 4 females) and odontogenic kerato cyst in 6(15.0\%) cases. Table No. II

The treatment modalities included marsupialization in $13(32.5 \%)$ patients, enucleation in $15(37.5 \%)$, and enucleation with curettage in $07(17.5 \%)$, by intraoral approach. Five cases (12.5\%) with Marsupialization followed by enucleation. Table No. II

The main finding in this study was that there was no association or insignificant difference of types of cysts with age and gender. These types of cysts may occur equally in both male and female ( $p$ value $>0.05$ ) Chart No.1

TABLE I: BASELINE CHARACTERISTICS OF THE PATIENTS $(n=40)$

\begin{tabular}{|l|c|c|}
\hline \multicolumn{1}{|c|}{ Age (in years), } & Frequency & Percentage \\
\hline Mean + SD (Range) & $\begin{array}{c}29.41+7.62 \\
\text { (18 to } 60 \text { years) }\end{array}$ & - \\
\hline Age in groups: & & \\
18 to 30 years & 17 & $42.5 \%$ \\
41 to 40 years 50 years & 13 & $32.5 \%$ \\
51 to 60 years & 08 & $20.0 \%$ \\
Gender: & 02 & $05.0 \%$ \\
Male & 27 & $67.5 \%$ \\
Female & 13 & $32.5 \%$ \\
Side involved: & 12 & $30.0 \%$ \\
Left & 28 & $70.0 \%$ \\
Right & & \\
\hline Clinical findings & 33 & $82.5 \%$ \\
Swelling & 31 & $77.5 \%$ \\
Aspiration of fluids & 25 & $62.5 \%$ \\
Discharge & 22 & $55.0 \%$ \\
Pain & 01 & $2.5 \%$ \\
Numbness & & \\
Radiographic findings: & & $85.0 \%$ \\
Unilocular & 34 & $10.0 \%$ \\
Multilocular & 04 & $05.0 \%$ \\
Mixed & 02 & $12.5 \%$ \\
ill defined & 05 & $87.5 \%$ \\
Well defined & 35 & \\
\hline
\end{tabular}


TABLE II: DIAGNOSIS AND TREATMENT OF THE PATIENTS $(n=40)$

\begin{tabular}{|l|c|c|}
\hline & Frequency & Percentage \\
\hline Diagnosis: & & \\
Periapical or radicular cyst & 21 & $52.5 \%$ \\
Dentigerous cyst & 11 & $27.5 \%$ \\
Odontogenic Keratocyst & 06 & $15.0 \%$ \\
Median mandibular cyst & 01 & $2.5 \%$ \\
Others & 01 & $2.5 \%$ \\
& & \\
Treatment: & 15 & $37.5 \%$ \\
Enucleation & 13 & $32.5 \%$ \\
Marsupialization & 07 & $17.5 \%$ \\
Enucleantion with curettage & 05 & $12.5 \%$ \\
Marsupiliazation followed & & \\
by nucleation & & \\
\hline
\end{tabular}

CHART I:

DISTRIBUTION OF PATIENTS ACCORDING TO

DIAGNOSIS WITH GENDER $(n=40)$

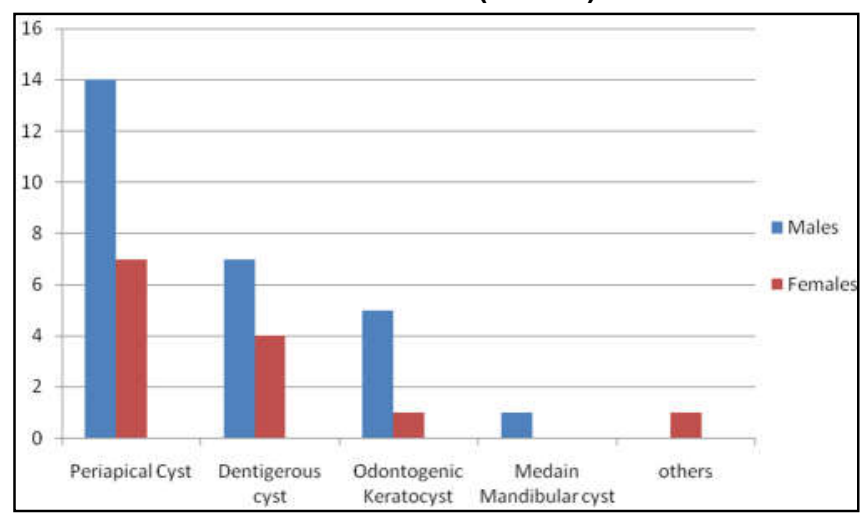

radicular cyst was most common $52.5 \%$; this observation was similar in other studies ${ }^{12-14}$. However studies conducted in Mexican population inflammatory cyst was less common than developmental cyst ${ }^{8}$.

This is also in agreement with local study conducted by Akram $S$ et al. in Karachi, the radicular cysts was present in $53 \%$ cases as it was frequently analyzed in his study - an observation that corresponds with the literature ${ }^{11-14}$. Radicular cystic lesions results due to pulpal necrosis and hence are considered to be inflammatory by nature ${ }^{3}$.

Several studies have proven that there was significant difference in gender patients, inspite of changes in sample size ${ }^{12,14,15}$.

The second most frequently diagnosed lesionwas the follicular/dentigerous cyst, representing $27.5 \%$ of the total, which is again coincident with the figures found in the literature ${ }^{11,13}$.

Radicular cysts are mostly treated in private clinics while this study was conducted in oral maxillofacial surgery department of an academic place.

It was observed by Mosquita-Taylor et $\mathrm{al}^{15}$ that patients who are visiting private clinics; they have common incidence of Developmental odontogenicsystes whereas those patients who are going to public health services; they have higher frequency of inflammatory odontogenic cysts ${ }^{15}$.

In disagreement of the study of Oshsenius and Leddesma-Montes and agreement of some other studies, male ratio was reported predominant as $\mathrm{M} / \mathrm{F}$ ratio of $1.5^{9,15}$

In the present study, the prevalence was high in male

TABLE III: DISTRIBUTION OF PATIENTS ACCORDING TO DIAGNOSIS WITH AGE IN GROUPS $(n=40)$

\begin{tabular}{|l|l|l|l|l|l|}
\hline \multicolumn{1}{|c|}{ Type of cyst } & \multicolumn{1}{|c|}{$\begin{array}{c}18 \text { to } 30 \\
\mathrm{n}=17\end{array}$} & \multicolumn{1}{c|}{$\begin{array}{c}31 \text { to } 40 \\
\mathrm{n}=13\end{array}$} & $\begin{array}{c}41 \text { to } 50 \\
\mathrm{n}=8\end{array}$ & $\begin{array}{c}51 \text { to } 60 \\
\mathrm{n}=02\end{array}$ & \multicolumn{1}{|c|}{ Total } \\
\hline Periapical or radicular cyst & $10(58.8 \%)$ & $09(69.2 \%)$ & $01(12.5 \%)$ & $01(50 \%)$ & $21(52.5 \%)$ \\
Dentigerous cyst & $05(29.4 \%)$ & $04(30.7 \%)$ & $01(12.5 \%)$ & $01(50 \%)$ & $11(27.5 \%)$ \\
Odontogenic Keratocyst & $03(17.6 \%)$ & $02(15.3 \%)$ & $01(12.5 \%)$ & 0 & $06(15.0 \%)$ \\
Median mandibular cyst & 0 & 0 & 0 & 0 & $01(2.5 \%)$ \\
Others & 0 & 0 & 0 & 0 & $01(2.5 \%)$ \\
\hline
\end{tabular}

\section{DISCUSSION}

Among the oral cystic lesions one of the most prevalent are odontogenic cyst with similar radiographic, clinical diagnosis but required careful examination of clinical, radiographic and histhopathological characteristics ${ }^{11}$.

The knowledge about the prevalence of odontogenic cysts and their common sites of appearance is very important for dental surgeons or other dental doctors because it helps to determine a perfect clinical identification ${ }^{11}$.

Comparing to other reported studies, we found that subjects; this is because of more susceptibility towards trauma and worse oral hygiene ${ }^{16}$.

In many studies it has been shown that the most prevalent and common location of OCs is in mandible regions mostly located in posterior area. On the opposite odontogenickerato cysts are commonly found in the anterior region/area ${ }^{13,16}$.

Most of the clinical features found in patients was swelling with odontogenickarato cyst and among those $50 \%$ of the patients complained feeling of pain while in some cases displacement of tooth and dental luxation was also observed.

Among the features of odontogenickerato cyst were a 
unilocular, corticated, well-defined radiolucency, however in some patients multilocular radiolucency was observed in Panoramic radiographs.

Odontogenicketatocyst were analyzed in patients who were in their twenties and thirties respectively ${ }^{13,17}$. Higher age distribution was established in other studies compare to this study ${ }^{18}$. These findings were harmonious with other researches ${ }^{19}$. while in respect to resorption of root and tooth displacement were shown in 4 and 8 cases $^{19}$.

In our study dissimilarly the radicular cysts were painful as compare to other studies ${ }^{20}$ this could be because of secondary infection or patients late refer for treatment.

The radicular cysts were found as coticatedunilocular, round radiolucency. Root resorption and tooth displacement were also reported compare to other studies ${ }^{21}$.

On radiographs the dentigerous cysts were shown as coticated, unilocular, well-defined radiolucency. Tooth displacement, feeling of pain, dental luxation and bucco-lingual expansion was reported in clinical examination. Compare to other studies the i.e. OKC cyst were observed in area or mandibular $3^{\text {rd }}$ molar more commonly ${ }^{11,13}$.

In some aspects the results of this study were in concurrence with earlier studies but differences were found related to living environment, racialism and lifestyle.

\section{CONCLUSION}

Evaluation of the results of this study shows that radicular cyst is the most common odontogenic cyst, coincident with the prevalence of dental caries.

Learning of the natural and histological conduct of odontogenic cysts and their recurrence are key viewpoints for guaranteeing early identification and satisfactory treatment. Further studies with larger sample size are required to examine these possibilities.

\section{REFERENCES}

1. Johnson NR, Gannon OM, Savage NW, Batstone MD. Frequency of odontogenic cysts and tumors: a systematic review. J Investig Clin Dent 2014; 5 (1): 9-14. doi: 10.1111/jicd.12044.

2. Pappalardo S, Guarnieri R. Randomized clinical study comparing piezosurgery and conventional rotatory surgery in mandibular cyst enucleation. J Craniomaxillofac Surg 2014; 42(5):e80-5. doi: 10.1016/j.jcms.2013.06.013.

3. Akram S, Naghma, Ali MA, Shakir MM. Prevalence of Odontogenic Cysts and Tumors in Karachi, Pakistan. J Dow Uni Health Sci 2013; 7 (1): 20-24.
4. Varkhede A, Tupkari JV, Mandale MS, Sardar M. Odontogenic tumors: a review of 60 cases. J Clin Exp Dent 2010; 2(4): e183-6.

5. Naz I, Mahmood MK, Akhtar F, Gillani SM. Clinicopathological analysis of odontogenic cysts in a selected Pakistani population. Biomedica 2012; 28(Jan-Jun): 61-5.

6. Ali K, Munir F, Rehman A, Abbas I, Ahmad N, Akhtar MU. Clinico-radiographic study of odontogenic cysts at a tertiary care centre. J Ayub Med Coll Abbottabad 2014; 26(1): 92-4.

7. Curé JK, Vattoth $S$, Shah R. Radiopaque jaw lesions: an approach to the differential diagnosis. Radiographics 2012; 32(7): 1909-25. doi: 10.1148/rg.327125003.

8. Núñez-Urrutia S, Figueiredo R, Gay-Escoda C. Retrospective clinicopathological study of 418 odontogenic cysts. Med Oral Patol Oral Cir Bucal 2010; 15(5): e767-73.

9. Mirhaidari S, Murthy A. Management of a Dentigerous Cyst in a Child with Robin Sequence. Arch Plast Surg 2017; 44(5): 434-38. doi: 10.5999/aps.2017.44.5.434

10. Wali GG, Sridhar V, Shyla HN. A study on dentigerous cystic changes with radiographically normal impacted mandibular third molars. J Maxillofac Oral Surg 2012; 11(4): 458-65. doi: 10.1007/s12663-011-0252-7

11. Ochsenius G, Escobar E, Godoy L, Penafiel C. Odontogenic cysts: analysis of 2.944 cases in Chile. Med Oral Patol Oral Cir Bucal 2007; 12(2): E85-91.

12. Baghaei $F$, Zargaran $M$, Najmi $H$, Moghimbeigi $A$. A Clinicopathological Study of Odontogenic Cysts and Tumors in Hamadan, Iran. J Dent(Shiraz) 2014; 15(4): 167-172.

13. Phulambrikar T, Vilas Kant S, Kode M, Magar S. Cone Beam Computed Tomography Findings in Calcifying Cystic Odontogenic Tumor Associated with Odontome: A Case Report. J Denist(Shiraz) 2015; 16(4): 374-379.

14. Prockt A, Schebela C, Maito F, Sant-Ana Filho M, Rados P. Odontogenic cysts: analysis of 680 cases in Brazil. Head Neck 2008; 2(3): 150-56. doi: 10.1007/s12105-008-0060-7

15. de Souza LB, Gordón-Núñez MA, Nonaka CF, De Medeiros MC, Torres TF, Emiliano GB. Odontogenic cysts: Demographic profile in a Brazilian population over a 38-year period. Med Oral Patol Oral Cir Bucal 2010; 15(4): e583-90.

16. Meningaud JP, Oprean N, Pitak-Arnnop $P$, Bertrand JC. Odontogenic cysts: a clinical study of 695 cases. J Oral Sci 2006; 48(2): 59-62.

17. MacDonald-Jankowski DS. Glandular odontogenic cyst: Systematic review. Dentomaxillofac 
Radiol 2010; 39(9): 127-39. doi: 10.1259/ dmfr/30943934.

18. Avelar RL, Antunes AA, Carvalho RW, Bezerra PG, Oliveira Neto PJ, Andrade ES. Odontogenic cysts: a clinicopathological study of 507 cases. J Oral Sci 2009; 51(4): 581-6.

19. Han PP, Nagatsuka $\mathrm{H}$, Siar $\mathrm{CH}$, Tsujigiwa $\mathrm{H}$, Gunduz M, Ramamura R, et al . A pigmented calcifying cystic odontogenic tumor associated with compound odontoma: a case report and review of literature. Head \& Face Medicine 2007; 3: 35.
doi:10.1186/1746-160X-3-35.

20. Avril L, Lombardi T, Ailianou A, Burkhardt K, Varoquaux $A$, Scolozzi $P$, et al. Radiolucent lesinos of the madndible: a pattern-based approach to diagnsosis. Insights Imaging 2014; 5 (1): 85-101. doi: 10.1007/s13244-013-0298-9.

21. Koseoglu BG, Atalay B, Erdem MA. Odontogenic cysts: a clinical study of 90 cases. J Oral Sci 2004; 46(4): 253-7.

\section{楼}

AUTHOR AFFILIATION:

Dr. Lovekesh Kumar (Corresponding Author) Department of Oral Maxillofacial Surgery Liaquat University of Medical \& Health Sciences (LUMHS), Jamshoro, Sindh-Pakistan.

Email: drlovelalwani@yahoo.com

Dr. Suneel Kumar Punjabi

Associate Professor

Department of Oral Maxillofacial Surgery

LUMHS, Jamshoro, Sindh-Pakistan.

Dr. Sikander Munir Memon

Research Officer / Associate

Department of Community Dentistry

LUMHS, Jamshoro, Sindh-Pakistan.

Dr. Hira Yousuf

Resident

Department of Oral Maxillofacial Surgery

LUMHS, Jamshoro, Sindh-Pakistan.

Dr. Shuja Aslam

Resident

Department of Operative Dentistry

LUMHS, Jamshoro, Sindh-Pakistan. 